\title{
O RESPONSÁVEL LEGAL É DE FATO O RESPONSÁVEL? UM QUESTIONAMENTO ÉTICO-LEGAL SOBRE 0 TERMO
}

\section{Júlio César fontana-Rosa e Reinaldo Ayer de Oliveira*}

Trabalho realizado departamento de Medicina Legal, Ética Médica, Medicina Social e do Trabalho da Faculdade de Medicina da Universidade de São Paulo, São Paulo, SP

* Correspondência:

Rua Teodoro Sampaio, 115

São Paulo - SP

CEP 05405-000

rayer@usp.br

\begin{abstract}
RESUMO
Os autores discutem o significado ético e jurídico da expressão "responsável legal", questionando seus limites. Demonstram que de fato ela não atende satisfatoriamente o que se denomina responsabilidade legal, pois para tanto teria que encontrar amparo nos códigos e normas legais, o que, de fato, não acontece. Assim, a expressão representante legal pode não possibilitar ao profissional, quando de sua utilização respaldo ético e legal normativo a sua atividade profissional.
\end{abstract}

UnITERMOS: Consentimento do representante legal. Ética médica. Responsabilidade civil.

\section{INTRODUÇÃO}

São várias as situaç̧ões na prática médica, seja para fins de diagnóstico, prognóstico e tratamento, em que a pessoa, objeto da atenção, não se encontra em condições de expressar sua vontade. Este impedimento pode ser por motivo de menoridade ou por causa de transtornos mentais. Estes últimos podem ser de caráter transitório ou permanente. Dentre as causas transitórias temos os casos de estados confusionais (distúrbios metabólicos, traumas cranianos, etc), ou de inconsciência (em estado de coma ou não) e, nos duradouros os transtornos mentais (permanentes) e os estados de coma definitivo.

O profissional médico, quando perante a um paciente nesta situação, procura definir uma pessoa que seja "responsável" e com ela decide pela realização ou não de um procedimento.

Esta pessoa é definida então como "responsável legal". O Código de Ética Médica utiliza a expressão, no artigo 59:

É vedado ao médico - "Deixar de informar ao paciente o diagnóstico, o prognóstico, os riscos e objetivos do tratamento, salvo quando a comunicação direta ao mesmo possa provocar-Ihe dano, nesse caso, a comunicação ser feita ao representante legal".

Para a utilização da expressão "legal" inserida ao lado de responsável, é necessário que se atenda ao que determina a legislação vigente. Entretanto, raramente aquele que a companha o paciente é de fato seu responsável legal. Ou seja, detentor do poder familiar, tutor ou curador, figuras jurídicas que são reconhecidas legalmente como aquelas que assumem a responsabilidade de alguém para com o outro.

As decisões tomadas pelo médico nos seus atos com aqueles pacientes sem condições de decidir, mesmo quando apoiadas no consentimento dado pelos "responsáveis legais", podem responder pelas conseqüências seja no plano ético, seja no plano legal. Neste último, no âmbito da justiça, os desdobramentos podem se dar nas diferentes esferas, mas, especialmente na civil relacionados entre outros aos custos do tratamento e processos de indenizações por supostos erros do profissional e na esfera penal em ações de danos pessoais (lesões corporais).

Por isso, é importante que o profissional entenda que: nem sempre o responsável pelo paciente é, de fato, ética e legalmente assim reconhecido. A condição de responsável legal é um procedimento que o médico e as instituições de saúde, pública e privada, encontraram para tentar dividir suas responsabilidades nos casos de pacientes sem condições de discernir quando do atendimento. Embora compreensível esta necessidade, do ponto de vista jurídico, o procedimento acaba por se constituir em uma burla do processo legal e pode provocar importante questionamento ético e jurídico, por parte do paciente depois de cessada sua incapacidade ou por determinação dos herdeiros quando de sua morte.

Definindo a pessoa no âmbito dos seus direitos

De acordo com a Lei n 10.406, de 10 de janeiro de 2002, que instituiu o Código Civil Brasileiro, no livro que trata das pessoas, em seu Capítulo I, Da Personalidade e Da Capacidade, temos:

"Artigo lo - Toda pessoa é capaz de direitos e deveres na ordem civil".

O legislador teve, inclusive, o cuidado de estabelecer o início destes direitos:

"Art. 2ํ A personalidade civil da pessoa começa do nascimento com vida; mas a lei põe a salvo, desde a concepção, os direitos do nascituro". (2)

Embora portadora de direitos, a pessoa, quando do seu nascimento por sua condição de imaturidade, necessita de uma outra pessoa, juridicamente capaz, que além de prover suas necessidades básicas, deverá também representá-lo nos atos da vida civil, receber uma herança, por exemplo.

Por conta de fatores que modificam a capacidade da pessoa para os atos da vida civil, como a idade, transtornos mentais, deficiência de fala ou de audição, características sócioculturais próprias o Código Civil prevê dois níveis de restrições da capacidade civil da pessoa. 
No primeiro, não reconhece qualquer capacidade para exercer pessoalmente os atos da vida civil, define no Art. 3 ○ que são absolutamente incapazes de exercer pessoalmente os atos da vida civil:

I - os menores de 16 anos;

II - os que, por enfermidade ou deficiência mental, não tiverem o necessário discernimento para a prática desses atos; e,

III - os que, mesmo por causa transitória, não puderem exprimir sua vontade.

Portanto, aqui já observamos a idade e os transtornos mentais como fatores limitantes. Entretanto, o legislador teve o cuidado de acrescentar a existência de outros fatores, embora transitórios, capazes de modificar o entendimento da pessoa. É o que ocorre quando pessoas (paciente ou pesquisando) estão em estado de inconsciência.

No segundo, o Código Civil reconhece que existe uma capacidade limitada, porém, capaz de ser representada em vários atos.

De acordo com o Art. 4ํ, são incapazes, relativamente a certos atos, ou à maneira de exercê-los:

I - os maiores de 16 e menores de 18 anos;

II - os ébrios habituais, os viciados em tóxicos, e os que, por deficiência mental, tenham o discernimento reduzido;

III - os excepcionais, sem desenvolvimento mental completo; e,

IV - os pródigos.

Parágrafo único. A capacidade dos índios será regulada por legislação especial.

Igualmente aqui localizamos situações com as quais o médico se defronta em suas atividades. Os casos descritos podem apresentar uma capacidade legal limitada para certos atos da vida civil. Não raro, o atendimento ao usuário de álcool ou drogas ou ao portador de retardo mental, coloca o profissional em conflito quanto à capacidade daquela pessoa deliberar sobre procedimentos médicos necessários para a mesma.

É importante frisar que não havendo um processo anterior que defina esta condição de capacidade reduzida; a pessoa é do ponto de vista jurídico, plenamente responsável e, portanto competente para tomar decisões. Quando o médico objetar esta condição de incapacidade, por entender quando do seu exame que a pessoa era incapaz, deverá estar atento para a possibilidade de ser chamado judicialmente para justificar seu entendimento. Este é um ponto de possível conflito nos casos de internação em psiquiatria.

Em psiquiatria, temos três modalidades de internação de acordo com a Lei n. 10.216, de 6 de abril de 2001, que prevê:

No Art. 60 - "a internação psiquiátrica somente será realizada mediante laudo médico circunstanciado que caracterize os seus motivos".

"Parágrafo único. São considerados os seguintes tipos de internação psiquiátrica:

I - internação voluntária: aquela que se dá com o consentimento do usuário;

II - internação involuntária: aquela que se dá sem o consentimento do usuário e a pedido de terceiro; e;

III - internação compulsória: aquela determinada pela Justiça." ${ }^{3}$

$\mathrm{Na}$ internação involuntária surge igualmente a condição do responsável legal, de forma mal definida.
No Art. 80 está expresso que "a internação voluntária ou involuntária somente será autorizada por médico devidamente registrado no Conselho Regional de Medicina do Estado onde se localize o estabelecimento de saúde".

A internação deverá: "no prazo de 72 horas, ser comunicada ao Ministério Público Estadual pelo responsável técnico do estabelecimento no qual tenha ocorrido, devendo esse mesmo procedimento ser adotado quando da respectiva alta".

Continuando, em seu parágrafo 2 o conclui que "o término da internação involuntária dar-se-á por solicitação escrita do familiar, ou responsável legal (grifo nosso), ou quando estabelecido pelo especialista responsável pelo tratamento.".

Novamente temos a figura do responsável legal sem uma clara definição. Se a internação for de um menor de idade, com pais definidos, poderemos localizar um responsável na figura de um deles. E, mesmo assim, poderemos ter conflitos de interesses entre ambos. Porém, teremos algum respaldo de um deles. Se for menor, sem um tutor definido, pergunta-se: quem será o seu responsável legal? Uma figura jurídica: o juiz de menor, sem dúvida. E no caso de pessoa maior de idade, sem discernimento. Um familiar?

O próprio artigo 8a, do Código Civil, diferencia o familiar do responsável legal, mostrando que a primeira condição (ser familiar) nãose identifica com a segunda (responsável legal), ou seja, são coisas distintas. Voltamos à mesma situação: quem é o responsável legal, neste caso.

Quando se trata de pessoa na maioridade o responsável legal, nos casos de pessoa interditada - por algum motivo, é aquele nomeado como curador.

O pródigo encontrado nos casos de transtornos bipolares do humor oferece constantes problemas pela impulsividade nas suas decisões. Entretanto, ele é responsável legal pelos seus atos, salvo por decisão judicial em contrário, por meio do processo legal de interdição, quando então alguém assume a condição, agora sim, de fato e de direito, de seu responsável legal.

No caso do desenvolvimento de um projeto de pesquisa em comunidades indígenas, o índio, quando não-aculturado e, portanto, a priori não conhecedor da legislação brasileira, visto que pertence a outra cultura, pode ser considerado parcialmente capaz. O fato do silvícola não aculturado ser parcialmente capaz deve ser levado em consideração quando o pesquisa dor solicitar o termo de consentimento livre e esclarecido. Neste caso, o responsável legal acha-se definido nos Estatutos da Fundação Nacional do Indio (FUNAl). ${ }^{4}$

OArt. $2^{\circ}$ dos Estatutos da FUNAl define suas finalidades:

I - exercer, em nome da União, a tutela dos índios e das comunidades indígenas não integradas à comunidade nacional;

Assim como nos demais casos em que a capacidade não é plena, temos a necessidade de que alguém ou de alguma instituição (no caso do índio a FUNAI) que represente juridicamente esta pessoa. Esta (in) capacidade de decisão do silvícola não-aculturado determina, entre outras, que a FUNAl após analisar os projetos de pesquisa, autorize ou não a realização da pesquisa nestas comunidades.

Embora eventualmente em condições de discernir, os surdosmudos que não conseguem se comunicar também necessitam de terceiros que os represente juridicamente. Co m relação aos 
surdos-mudos esta necessidade é cada vez menos freqüente por conta das instituições que os habilitam a se comunicar. Também o silvícola, pelo seu contato cada vez mais estreito com a sociedade, vem experimentando modificações na sua juridicidade a ponto de serem considerados imputáveis pelos seus crimes.

Portanto, excetuando-se o exposto nos parágrafos $3^{\circ}$ e $4^{\circ}$ pelo que consta do Art. 50 do Código Civil Brasileiro: "a menoridade cessa aos 18 anos completos, quando a pessoa fica habilitada à prática de todos os atos da vida civil".

O Código Civil, ainda com relaçãoà menoridade acima de 16 anos de idade, em seu parágrafo único do artigo $5^{\circ}$ determina que "cessará, para os menores, a incapacidade":

I - pela concessão dos pais, ou de um deles na falta do outro, mediante instrumento público, independentemente de homologação judicial, ou por sentença do juiz, ouvido o tutor, se o menor tiver 16 anos completos;

II - pelo casamento;

III - pelo exercício de emprego público efetivo;

IV - pela colação de grau em curso de ensino superior;

$V$ - pelo estabelecimento civil ou comercial, ou pela existência de relação de emprego, desde que, em função deles, o menor com 16 anos completos tenha economia própria.

Portanto, essas condições permitiriam ao menor de 18 e maior de 16 anos, exercerem pessoalmente sua condição de responder pelos atos da vida civil. Anteriormente aos 18 anos, quando não previstas as condições imediatamente acima (maioridade com 16 anos ou mais), a pessoa necessita de alguém juridicamente responsável pelos seus atos.

$\mathrm{Na}$ legislação há clara definição da figura do responsável legal para cada uma das situações acima: no caso de filhos menores, os pais são os responsáveis; no caso de menor de idade sem pais que assumam esta condição, têm-se o tutor igualmente designado em juízo, e para os maiores, com discernimento comprometido, são nomeados curadores.

Nos casos de menores sem pais, e maiores com discernimento comprometido, somente haverá a definição de tutores ou curadores respectivamente, após o devido processo legal que os estabeleçam. Anterior a um processo legal, todo maior de idade é, em princípio, capaz de se representar pessoalmente em todos os atos da vida civil.

Nos casos em que o maior de maneira indiscutível se mostrar incompetente para tomar decisões, o Estado poderá, provisoriamente, assumir a responsabilidade sobre o mesmo até a definição do responsável legal. Do mesmo modo se verifica com o menor sem pais, que ficará sob a guarda do Estado até a nomeação de um tutor.

Portanto, pelo exposto, se nãofoi definida legalmente esta curatela, não se pode falar em "responsável legal". Qualquer outro nome não define corretamente a condição legal pretendida.

Diferentes implicações podem advir do uso inadequado desta expressão.

Inicialmente, no que se refere aos valores materiais, surgem perguntas, como: a pessoa nominada como "responsável legal", em uma ficha de internação, pode assumir compromissos com as eventuais despesas necessárias para oatendimento de um paciente inconsciente? Pode decidir pela realização desta ou daquela cirurgia com implicações nos custos?
Se não houver uma sociedade legal entre o paciente e seu representante legal com contrato que permita esta decisão, nãose pode falar em um compromisso com respaldo legal. Ou seja, os custos recairão sim sobre o paciente ou seus herdeiros. Isto é claro e límpido.

Ainda no âmbito jurídico, prevê o artigo I 5 do Código Civil que: "Ninguém pode ser constrangido a submeter-se, com risco de vida, a tratamento médico ou intervenção cirúrgica". Na prática, o médico se vê às voltas com situações em que há risco de morte para a realização de um determinado procedimento, entendido como necessário, porém, o paciente encontra-se inconsciente e sem condições para decidir. Nestas situações o profissional busca uma autorização do nominado: "responsável legal". Quem seria esta pessoa que traria consigo a competência legal para esta decisão, não sendo o paciente considerado incapaz?

Nas situações em que o paciente não pode discernir, o médico, comumente, busca apoio nas pessoas próximas ao paciente, pois ele entende que as decisões não devem ser unicamente dele, pois estas poderiam ser interpretadas como uma forma de constrangimento. No entanto, observa-se que não há nenhum código ou norma que estabeleça critérios para a escolha desta pessoa. No caso de paciente maior, não interdito, a escolha desta pessoa vai atender apenas um reclamo ético, para conferir ao profissional este apoio nas decisões. Este seria apenas um acompanhante com diferentes graus de relação com o paciente e na dependência deste vínculo com maiores ou menores condições de opinar. Meramente, opinar, e não, decidir.

Pode-se inferir que esta pessoa, por ideal, seria o familiar mais próximo do paciente. Exemplificando, o cônjuge, filhos, pais e colaterais. No entanto, surge a necessidade de estabelecer uma graduação de preferência sobre quem deve opinar. No caso de opiniões divergentes entre, por exemplo, os filhos, qual seria o mais apto a ser o representante? (o mais velho, o mais próximo, o mais esclarecido?).

Curiosamente, no Artigo $8{ }^{\circ}$ da Lei n⿳ 10.216, de 6 de abril de 2001 , também conhecida como Lei Paulo Delgado, em seu $\S 2^{\circ} 0$ legislador faz distinção entre familiar e responsável legal. $\mathrm{O}$ artigo diz que "A internação voluntária ou involuntária somente será autorizada por médico devidamente registrado no Conselho Regional de Medicina do Estado onde se localize o estabelecimento". Ainda, conforme $\S 2 \circ$ "otérmino da internação involuntária dar-se-á por solicitação escrita do familiar, ou responsável legal, ou quando esta belecido pelo especialista responsável pelo tratamento." Portanto, nem mesmo a figura do familiar é aquela que se apresenta inquestionavelmente como a mais capaz de decidir. Embora se entenda que o termo "ou" ali observado ("... familiar ou representante legal..."), apenas apresenta o segundo como opção na falta do primeiro.

Novamente observamos a figura do "responsável legal" sendo evocada na Resolução CFM no 1.598/00 em seu artigo 160: "Nas internações involuntárias, o médico que realiza o procedimento faz constar do prontuário as razões da internação, bem como os motivos da ausência de consentimento do paciente neste caso, deve buscar o consentimento de um responsável legal." 5.

Não são incomuns decisões diferentes entre filhos com relação às condutas que devam ser tomadas no atendimento de seus progenitores. Mesmo entre pais, por vezes, surgem impasses. Igualmente observam-se, não raramente, diferenças nas decisões dos progenitores 
de um dos cônjuges com relaçãoà conduta decidida pelo outro. Neste último exemplo, temos os casos de internação compulsória ou suspensão de suporte avançado de vida que mantém vivo um dos cônjuges e não existe consenso entre os familiares envolvidos (pais do paciente discordando do cônjuge).

Embora o ato de ouvir os familiares seja altamente recomendável, isto por si só não exime o profissional de eventuais processos judiciais. Embora seja certo que processos podem surgir, pelos mais variados motivos, mesmo sem uma causa inicial consistente. E, por este motivo, devemos nos preparar para apresentar justificativas se, e quando, interpelados judicialmente.

\section{Conclusão}

Portanto, ampliar a discussão sobre o que se denomina de "responsável legal" se faz necessária visto que usamos rotineiramente esta expressão, inclusive com respaldo de decisões do Conselho Federal de Medicina que a utiliza regularmente e, pelo exposto, seu sentido legal é diferente daquele que lhe pretende atribuir.

Esta necessidade de definição dos limites jurídicos da expressão serve para orientar os médicos sobre que tipo de salvaguarda ética e legal a mesma nos possibilita quando for utilizada nos procedimentos seja com pacientes, seja com sujeitos de pesquisa.

\section{Agradecimento}

Sra. Dinaura Paulino Franco

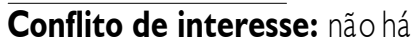

\section{SUMMARY}

IS the LEgally RESPONSIBLE PARTY INDEED RESPONSIBLE? AN ETHICAL-LEGAL QUESTION ON THE TERM

The authors discuss the legal and ethical meaning of the expression "Third-Party Consent" by questioning its limits. It is indeed shown that it does not satisfactorily meet what is called third-party consent because this would require legal endorsement by legal codes and norms which, infact does not occur. As such, the expression "third-party consent", whenever used, may not provide the professional with the normative, ethical and legal support needed for professional performance. [RevAssoc Med Bras 2008; 54(3): 279-82]

KEY wORDS: Third-Party consent. Medical ethics. Damage liability.

\section{REFERÊNCIAS}

I. Brasil. Resolução n. 1.246, de 8 de janeiro de 1988. Dispõe sobre o Código de Ética Médica [citado 21 Fev 2007]. Disponível em: http:// www.cremesp.org.br/library/modulos/legisla ca o/ versao_impressao.php?id $=2940$.

2. Brasil. Lei n. 10.406, de 10 de janeiro de 2002. Institui o Código Civil Brasileiro [citado 21 Fev 2007]. Disponível em: http:// www. planalto.gov. br/ccivil/eis/2002/ I 0406. htm.

3. Brasil. Lei n. 10.216, de 6 de abril de 200 I. Dispõe sobre a proteçãoe os direitos das pessoas portadoras de transtornos mentais e redireciona o modelo assistencial em saúde mental [citado 21 Fev 2007]. Disponível em: http://www. planalto.gov.br/ccivil_03/Leis/LEIS_200I/LI 02 I6.htm.

4. Brasil. Decreto n. 4.645, de 25 de março de 2003. Aprova o Estatuto e - Quadro Demonstrativo dos Cargos em Comissão e das Funções Gratificadas da Fundação Nacional do Índio - FUNAl, e dá outras providências [citado 21 Fev 2007]. Disponível em: http:// www.funai.gov.br/quem/egislacao/estatuto funai.htm.

5. Brasil. Conselho Federal de Medicina. Resolução n 1.598 , de 9 de agosto de 2000. É dever do médico assegurar a cada paciente psiquiátrico seu direito de usufruir dos melhores meios diagnósticos cientificamente reconhecidos e dos recursos profiláticos, terapêuticos e de reabilitação mais adequados para sua situação clínica [citado $7 \mathrm{Mar}$ 2007]. Disponível em: http://www.portalmedico.org.br/resolucoes/ cfm/2000/I 598_2000.htm. 